\title{
DNA fingerprinting used to test for family effects on precocious sexual maturation in two populations of Oncorhynchus tshawytscha (Chinook salmon)
}

\author{
DANIEL D. HEATH*, GEORGE K. IWAMA \& ROBERT H. DEVLIN $\dagger$ \\ Department of Animal Science and the Canadian Bacterial Diseases Network, University of British Columbia, 2357 Main \\ Mall, Suite 248, Vancouver, B.C., Canada V6T 1 Z4 and †Department of Fisheries and Oceans, Canada, West Vancouver \\ Laboratories, 4160 Marine Drive, West Vancouver, B.C., Canada V7V 1 N6.
}

\begin{abstract}
Two single locus Variable Number Tandem Repeat (VNTR) DNA probes were used to test for differences in allele distribution between precociously mature male and immature chinook salmon, Oncorhynchus tshawytscha. Two populations were examined: Robertson Creek (RC) adult salmon, and Nicola River (NR) freshwater juveniles, or parr. Genomic DNA was extracted from 74 RC precociously mature adult males ('jacks') and $94 \mathrm{RC}$ immature adults of the same age and from 45 NR precociously mature parr and 51 NR nonmaturing parr. The genomic DNA was hybridized with a single locus VNTR probe developed for chinook salmon (OtSL1), as well as one developed for Atlantic salmon, Salmo salar (Ssa1). The allele frequency distributions at both loci were significantly different for the RC jacks and immature fish, indicating a family effect on the incidence of precocious maturation in that population. No difference was found between the allele frequency distribution of the NR precocious and immature parr. A bin width sensitivity analysis showed that the comparisons of the allele frequency distributions were insensitive to the choice of bin size. No differences in heterozygosity were found between mature and immature fish at either locus for both stocks. Preliminary testing for family effects on phenotypes of interest, such as alternative life history strategies, can be performed using hypervariable VNTR DNA probes, prior to implementing costly and involved breeding programmes.
\end{abstract}

Keywords: allele binning, allele frequency distribution, jacking, precocious parr, VNTR.

\section{Introduction}

Coastal chinook salmon generally spend the first $6-8$ months of their life in freshwater and then undergo a complex physiological transformation (smoltification) and migrate to saltwater. However, some stocks from far upstream may have a longer freshwater residence of 18-30 months (Healey, 1991). Adult female chinook salmon typically return to freshwater to spawn after 2-5 years at sea, while males may sexually mature one or more years earlier than any of the females in their cohort. Such precocious sexual maturation in sea-run salmon ('jacking'), has been successfully modelled as an evolutionary stable strategy (ESS) in coho salmon, Oncorhynchus kisutch (Gross, 1985). In some populations, nonmigratory freshwater males may mature with-

*Present address and correspondence: Department of Biological Sciences, University of South Carolina, Columbia, S.C. 29208 , U.S.A. out ever entering the ocean environment and are defined as 'precocious parr' (Bernier et al., 1993). These mature males are extremely small, generally less than $20 \mathrm{~g}$ wet weight, but are capable of successfully fertilizing eggs (Robertson, 1957; Bernier et al., 1993). Precocious maturation of male freshwater parr is particularly common in Atlantic salmon, and has also been modelled using ESS theory (Bohlin et al., 1986; Leonardsson \& Lundberg, 1986). Only far upstream populations of chinook salmon exhibit such extreme precocious sexual maturation (Healey, 1991). It has thus been hypothesized that premigration sexual maturation may result from the high cost of the longer migration distance to the ocean for upstream populations, relative to coastal populations (Schaffer \& Elson, 1975; Taylor, 1989; Bernier et al., 1993). All of these hypotheses assume a heritable component to the incidence of precocious sexual maturation in chinook salmon populations. 
If there is a significant genetic component to the incidence of jacks (or precocious parr), full-sib families within the population should differ in the incidence of precocious maturation. For example, consider the extreme case of precocious sexual maturation controlled by a single gene. In such a case, all precociously maturing males within the population would be offspring from precociously mature males. Thus, a random sample of precociously mature male offspring would, on average, be more related than a random sample from the population (sired by all possible male parents). Consequently, jacks and precocious parr would be expected to have a genetic composition (and perhaps diversity) different from a random sample of the population. Since VNTR DNA is noncoding (Castelli et al., 1990; Stephan \& Cho, 1994), and hence under no direct selection pressure (Jarman \& Wells, 1989; Stephan \& Cho, 1994), highly variable VNTR loci would be ideal for testing for differences in genetic composition and diversity between jacks and the random-mated source population.

Multilocus DNA fingerprinting has been used to study genetic structure in populations of plants and animals (Gilbert et al., 1990; Rogstad et al., 1991; Wirgin et al., 1991; Triggs et al., 1992). There are, however, theoretical limitations to such applications (Lynch, 1991). Single locus VNTR DNA probes avoid many of the problems associated with multilocus probes (Lynch, 1991) and have been developed for a number of species (Taggart \& Ferguson, 1990; Amos et al., 1991; Bentzen et al., 1991; Burke et al., 1991; Hanotte et al., 1991; Kempenaers et al., 1992; Heath et al., 1993a). There have, however, been few applications of single locus probes in evolutionary or ecological studies. Amos et al. (1991) used multi- and single locus probes to measure relatedness in pods of pilot whales. Kempenaers et al. (1992) used single locus probes to determine male parentage in families of birds. There have also been extensive applications of human single locus VNTR DNA probes for medical and forensic purposes (Jeffreys et al., 1991; Wolff et al., 1991), as well as for demographical studies (Tynan et al., 1991; Balazs et al., 1992).

Here we describe the investigation of the genetic component to jacking in chinook salmon, and of precocious sexual maturation in chinook salmon under-yearling parr using two hypervariable single locus probes. Specifically we test the hypothesis that precociously mature chinook salmon have VNTR allele distributions different from a random sample of immature fish from the population. Two very different populations were studied; the 2-year-old jacks were from a coastal population while the under-yearling precocious parr were from a far upstream population.
A substantial genetic component to precocious maturation has already been demonstrated for jacking (Heath et al., 1994). The analysis of precocious maturation in the upstream chinook salmon parr is a novel application to test the hypothesis that precocious sexual maturation at the parr stage is heritable.

\section{Materials and methods}

\section{Fish stocks and sampling}

Robertson Creek adults The Robertson Creek stock (RC) were 2-year-old chinook salmon reared at the commercial production site of Yellow Island Aquaculture Ltd (YIAL, Quadra Island, British Columbia). The adult RC chinook salmon population was the progeny of single-pair fertilizations of ova from 15 females with sperm from an equal number of males. All parental fish were spawned on a single day during the 1987 spawning run and thus may not represent the stock as a whole. The $\mathrm{RC}$ fish were incubated in constant temperature water (average $8.2^{\circ} \mathrm{C}$ ), and reared in $3000 \mathrm{~L}$ rectangular tanks, then transferred to seawater netcages at 5-10 g average weight. The RC stock was reared to sexual maturity under typical commercial rearing conditions at YIAL (see Heath et al., 1991).

In the fall of 1989 approximately 150 jacks and 200 immature fish (aged 2 years) were taken at random from a single netcage (approximately 12000 individuals) at YIAL. Liver or testes samples were taken and frozen $\left(-20^{\circ} \mathrm{C}\right)$ until DNA was extracted. The jacks were unambiguously identified by secondary sexual characteristics (eg. dark skin color) and the expression of sperm.

Only females were used to represent the immature $\mathrm{RC}$ population. Since a large proportion of the males in the RC population were jacks (approx. 40 per cent), the immature males would not constitute a random sample of the population, and would thus bias the sample.

Nicola River parr The Nicola River stock (NR) were under-yearling chinook salmon parr from the Spius Creek Hatchery (see Bernier et al., 1993). The Nicola River (NR) fish were from a population generated from approximately 45 pair matings. The NR parr were incubated in ambient temperature water (range $1-14^{\circ} \mathrm{C}$ ), and reared (posthatch) in concrete raceways.

In the fall and early winter of 1989,60 precociously mature male parr were selected from the population of NR parr (aged less than 1 year) held at the Spius Creek hatchery (approx. 80000 individuals). The sexually mature parr were unambiguously identified as 
described in Bernier et al.(1993). At the same time, an approximately equal number of immature parr were also taken at random. The fish were individually wrapped in plastic and frozen $\left(-20^{\circ} \mathrm{C}\right)$. Later, the whole fish samples were dissected while still frozen and liver tissue was taken for DNA extraction.

The incidence of precocious sexual maturation in the NR population was very low (approx. 1-3 per cent of the population), thus Nicola River immature males approximate a random sample from the population. The population sample consisted of about equal numbers of immature males and females.

\section{DNA extraction and Southern transfer}

The DNA extraction protocol for all samples is described in Devlin et al. (1991) and sex was determined for immature fish using the Y-chromosomal probe developed by Devlin et al. (1991). For Southern analysis, $3 \mu \mathrm{g}$ of DNA from 74 jacks and 94 females from the RC stock and 45 precociously mature male parr and 51 immature parr (mixed sex) from the NR stock were digested overnight with the restriction endonuclease HaeIII, size-fractionated by gel electrophoresis, and transferred to $20 \mathrm{~cm} \times 25 \mathrm{~cm}$ nylon membranes (Hybond N, Amersham Corp.) as described in Sambrook et al. (1989). DNA from one individual was run on all gels to act as a standard for verifying the band position determinations. Molecular weight standards (1 kb ladder DNA - Gibco-BRL) were run on both end lanes and in the middle lane of all gels. Polaroid photographs were taken of the UV transilluminated gels $(0.5 \mu \mathrm{g} / \mathrm{mL}$ ethidium bromide added to the gels) with a ruler included for reference to allow band size determination based on the positions of the molecular weight standards.

\section{Probes and hybridization}

The membranes were hybridized with two probes: OtSL1, a chinook salmon hypervariable single locus probe (SLP) developed by the authors using directed amplification of minisatellite-region DNA (DAMD Heath et al., 1993a), and Ssa1, a highly variable SLP developed for Atlantic salmon (Bentzen \& Wright, 1993). The membranes were prehybridized for $3-5 \mathrm{~h}$ in a solution of 7.0 per cent sodium dodecylsulphate (SDS), $\quad 1.0 \mathrm{~mm}$ ethylenediaminetetraacetic acid (EDTA), $0.263 \mathrm{M} \mathrm{Na}_{2} \mathrm{HPO}_{4}$, and 1.0 per cent bovine serum albumin (fraction $\mathrm{V}$ ), following Westneat et al. (1988), and then hybridized with random-primed radio-labelled OtSL1 probe (Feinberg \& Vogelstein, 1984 ) overnight at $68^{\circ} \mathrm{C}$. The membranes were washed in $0.2 \times \mathrm{SSC}(0.3 \mathrm{M} \mathrm{NaCl}, 0.3 \mathrm{M}$ sodium citrate, $\mathrm{pH}$
$7.0)$, twice at room temperature and once at $68^{\circ} \mathrm{C}$, then exposed to $\mathrm{X}$-ray film for 1-2 days with an intensifying screen at $-70^{\circ} \mathrm{C}$. Following autoradiography, the membranes were stripped of probe (following manufacturers instructions - Amersham Corp., IL, USA), then rehybridized with Ssa1 following the same protocols, with the hybridization and final wash temperatures reduced to $55^{\circ} \mathrm{C}$.

The analysis of the RC jacks and immature females assumed no sex-linkage for either OtSL1 or Ssa1. Both probes were extensively checked for sex-linkage using full- and half-sib families of chinook salmon from the RC population. Furthermore, DNA from 24 immature $\mathrm{RC}$ males was hybridized with both probes, and the resulting allele distribution was compared to the immature RC females. No significant differences were found $(P>0.30)$.

\section{Allele scoring}

To determine the molecular size of each allele, a linear relation was generated between the natural logarithm (ln) of the position (with respect to the loading wells) and the $\ln$ of the size $(\mathrm{kb})$ of the marker bands for each gel, based on measurements made on the Polaroid photos. Distance measurements (to the nearest $\mathrm{mm}$ ) were made from the loading wells to the top (closest to loading wells) of all bands (alleles) for the OtSL1- and Ssa1-probed autoradiographs. These distance measurements were converted to fragment sizes (in $\mathrm{kb}$ ) using the $\ln -\ln$ relation described above. The $\ln -\ln$ transformation linearized the data over a greater range of molecular weights than the semi-log transformation. The individual that was run on all gels was used to confirm the allele size conversion for each gel. All patterns which consisted of a single band (i.e. Fig. 1, lane 6 in OtSL1 and Ssa1) were scored as homozygous for the same allele, although hemizygosity could not be ruled out.

\section{Allele binning}

Once all individuals had both OtSL1 and Ssa1 allele sizes scored, an estimation of the error associated with the calculated allele sizes was made. Error in allele size originated from two sources, within-gel error (measurement errors, nonuniform migration speed, etc.) and between-gel error. The repeated individual lane allowed an estimation of the range of between-gel error while frequently occurring 'common alleles' (e.g. Fig. 1, lanes 2-5, and 7 for OtSL1) allowed an estimate of the within-gel error. The within- and between-gel errors were combined to give an estimate of the total observed error. 


\section{OtSL1}

\section{Ssa 1}

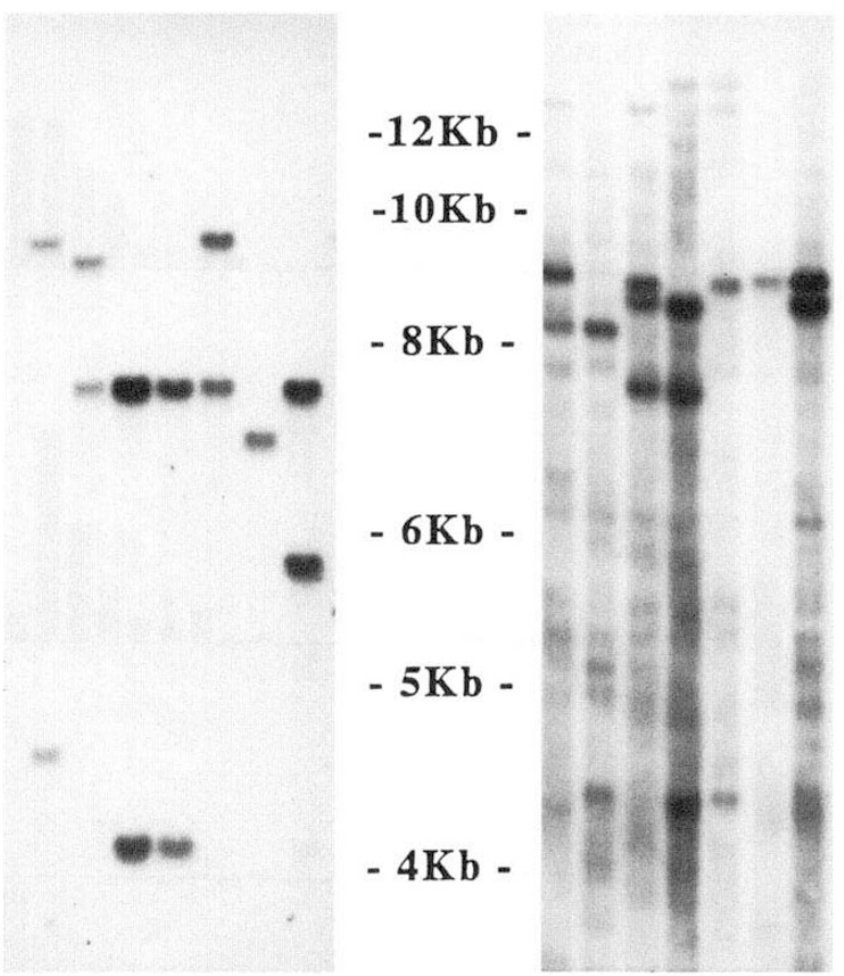

Fig. 1 Autoradiographs of HaellI-digested genomic DNA from seven immature Robertson Creek (RC) chinook salmon hybridized with the OtSL1 and Ssa1 single locus VNTR probes.

Allele 'bins' were defined as allele size ranges slightly greater than the total observed error range. This range represented the 93-97 per cent confidence limits for an $8.0 \mathrm{~kb}$ allele. Since the error range increased with allele size, the bin width was set using a simple linear function based on \pm 2.5 per cent of the median allele size for OtSL1 and \pm 3.75 per cent of the median allele size for Ssa1. A series of bins was defined that spanned the range of measured allele sizes (for the two probes and stocks). The bins were then shifted by $0.1 \mathrm{~kb}$ increments and the range of bin shifts that allowed the alleles that were known to be of the same size to fall into a single bin was determined. The bin shift was set to the centre of this range. The use of such an allele binning procedure has some limitations (Pascali et al., 1991); however, the limitations tend to mask true allelic variation and thus, for our application, make the analysis more conservative.

The choice of bin width is critical to the analysis of allele frequency distribution. We chose bin widths based on empirical estimates of between- and withingel errors; however, to test the sensitivity of our analyses to the choice of bin width, a series of bin widths (wider and narrower than those used) was generated. The resulting allele frequency distributions were statistically analyzed as described below and the resulting significance levels were then plotted against bin width.

\section{Data analysis}

Allele distribution Log-linear models were used to test for differences in the allele frequency distribution between the jacks and the immature adult chinook salmon, as well as between the precocious parr and the immature controls (Fienberg, 1970). To avoid excessive numbers of sparse cells (i.e. fewer than five alleles/bin), adjacent low frequency bins were combined. However, the combined bin analyses gave the same qualitative results as the analyses without combining cells, and the frequency of sparse cells was low $(<5$ per cent $)$.

Heterozygosity Differences in the frequency of heterozygous loci between the RC jacks and females and NR precocious and immature parr were tested using 2-way contingency table analyses (Sokal \& Rohlf, 1981).

\section{Results}

The OtSL1 and Ssa1 probes both produced easily identified bands, although Ssa1 produced higher background signal (Fig. 1). Approximately 20 per cent of the salmon probed with Ssa1 yielded three distinct bands (e.g. the third and fourth lanes in Fig. 1-Ssa1). The cause of this is unclear (it may arise from the residual tetraploid nature of salmonids-Bentzen \& Wright, 1993); however, in such cases all three bands were scored as alleles.

\section{Allele distribution}

The RC jack and immature female allele frequency distributions (Fig. 2) were significantly different at both the OtSL1 $\left(G_{9}=57.9, P<0.001\right)$ and the Ssa1 loci $\left(G_{12}=45.1, P<0.001\right)$. The NR precocious and immature parr allele frequency distributions (Fig. 3) were not significantly different at either the OtSL1 $\left(G_{7}=11.1, P>0.13\right)$ or the Ssa1 loci $\left(G_{9}=15.2\right.$, $P>0.08$ ). If single bands were scored as hemizygotes, rather than homozygotes, the analyses gave the same qualitative results, although the significance levels were slightly changed.

The choice of bin width was critical to the interpretation of the analysis for the $\mathrm{RC}$ population only at extremely large bin widths (Fig. 4). Our choice of bin width was within a range that was statistically insensitive to changes in bin width (Fig. 4), making our results 
OtSL1
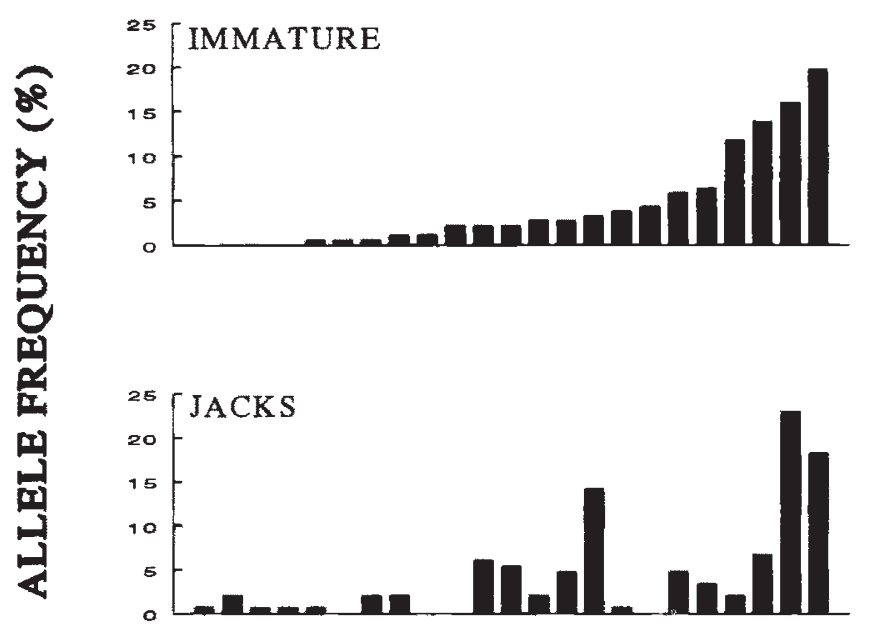

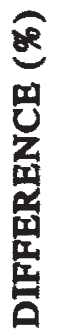

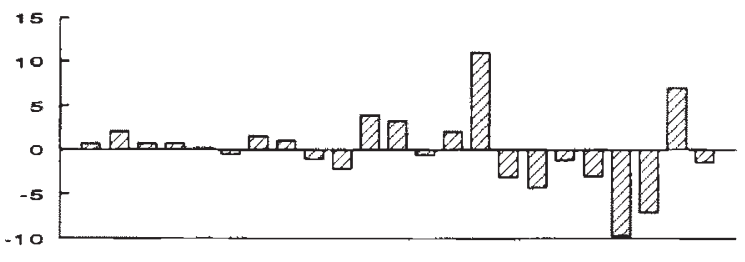

Ssa 1
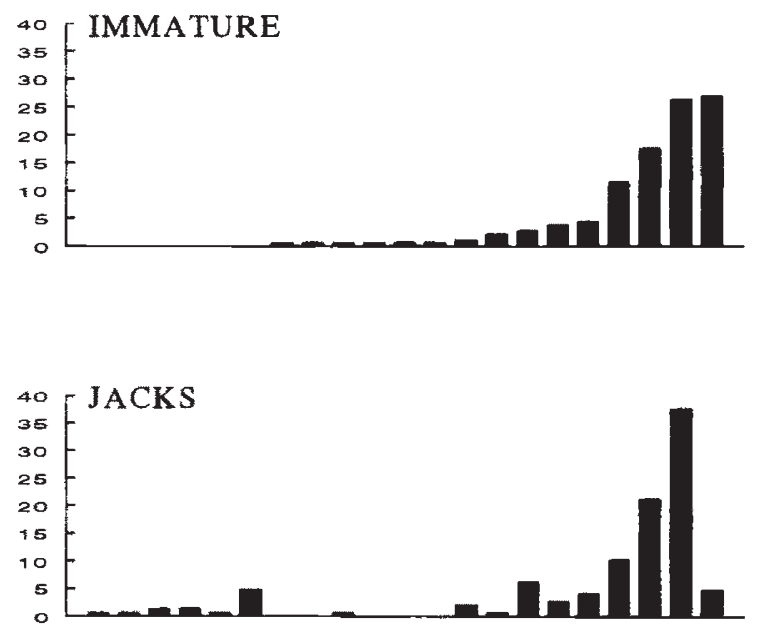

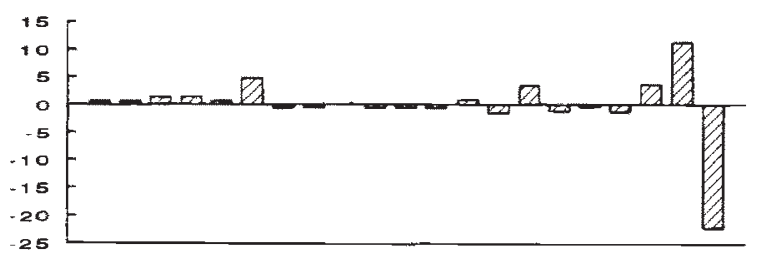

\section{ALLELES}

Fig. 2 Allele frequencies (per cent) at the OtSL1 and Ssa 1 loci for Robertson Creek (RC) adult chinook salmon (immature, and mature jacks). The allele frequencies are arranged in ascending magnitude for the immature sample. The differences between the jack and immature allele frequencies are shown in the lower panels. There are significant differences between the allele frequency distributions of the jacks and the immature fish at both loci.

robust. Bin width was not as critical for the NR populations, since the results were not significant over virtually the entire bin width range (Fig. 4). It is clear, however, that some form of bin width sensitivity analysis is necessary to validate significance levels generated by allele frequency distribution comparisons based on allele binning procedures.

\section{Heterozygosity}

There were no significant differences in heterozygosity between sexually mature and immature fish at either locus, or in either stock (Table 1). The overall heterozygosity for the RC and NR stocks combined was 82 per cent for the OtSL1 locus and 91 per cent for the Ssa1 locus.

\section{Discussion}

The analysis of the allele frequency distributions for the OtSL1 and Ssa1 loci showed that jacks represented a genetic subset of the RC population studied here, i.e. there were significant differences in the allele frequency distributions at both loci. Some alleles were over-represented in the jacks, while others were underrepresented (see Fig. 2). This study could not distinguish between the differences in allele frequency distribution due to genetic effects (i.e. certain families being predisposed to jacking) and nongenetic maternal fects. However, there is evidence that nongenetic aternal effects are generally small for chinook salmon 1st 6 months of age (see Heath et al., 1993b). The analysis of jacking in the $\mathrm{RC}$ population showed 


\section{OtSL1}
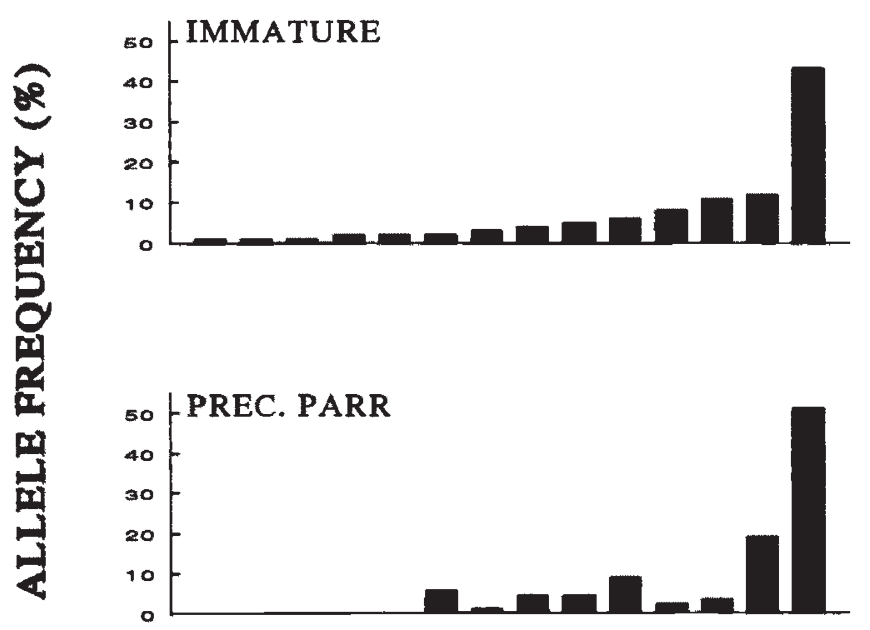

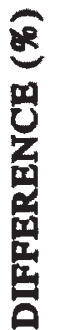

\section{Ssa 1}
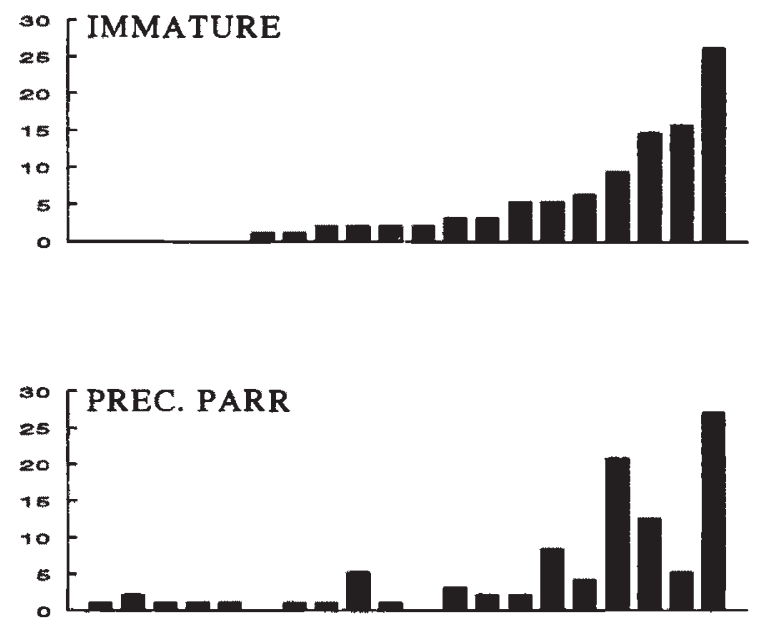

\section{ALLELES}

Fig. 3 Allele frequencies (per cent) at the OtSL1 and Ssa1 loci for the Nicola River (NR) chinook salmon parr (immature parr, and precociously mature parr). The allele frequencies are arranged in ascending magnitude for the immature sample. The differences between the precocious parr and immature allele frequencies are shown in the lower panels. There were no significant differences between the allele frequency distributions of the precocious parr and the immature parr for either locus.

Fig. 4 Results of the bin width sensitivity analysis of the log-linear model used to test for differences between allele frequency distributions. Significance level of the log-linear analysis is plotted against a range of bin widths (defined as a percentage of the median bin size in $\mathrm{kb}$ ). Squares joined by solid lines represent the $\mathrm{RC}$ population, while circles joined by dashed lines represent the NR population. Open symbols indicate Ssa1 locus results and filled symbols indicate OtSL1 locus results. The bin widths used in our analyses are identified on the $x$-axis, and the $P=0.05$ level is marked with a dashed line.

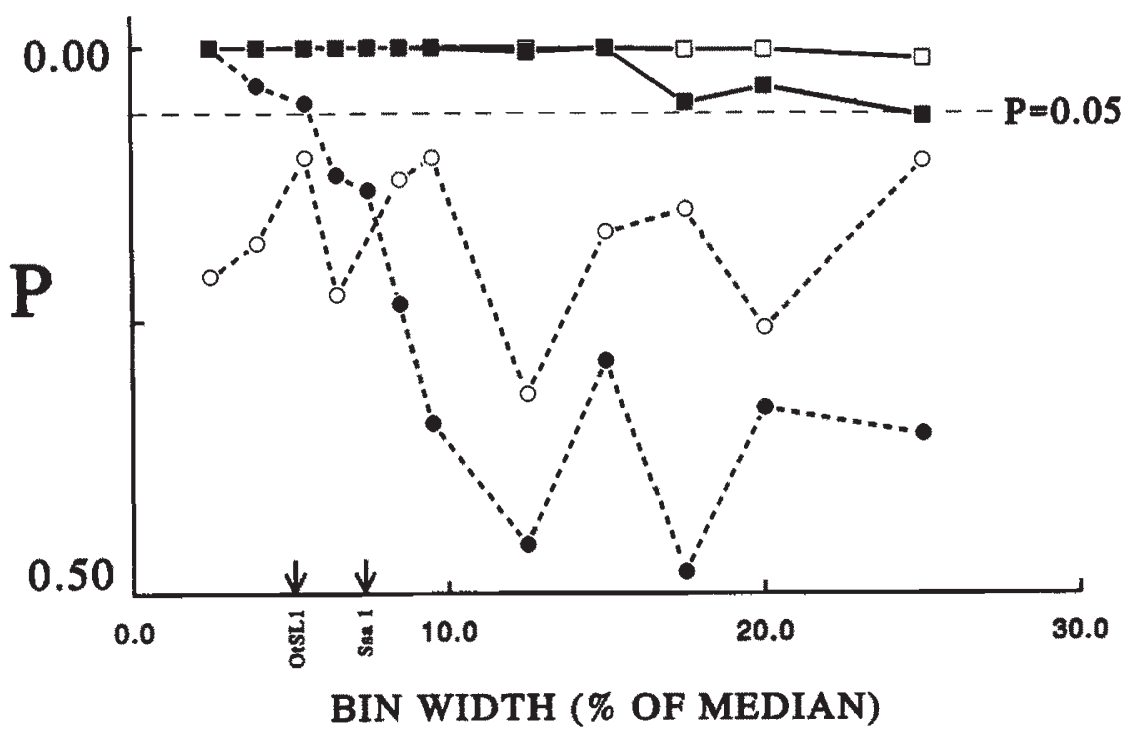


Table 1 The frequency of heterozygote sexually mature and immature chinook salmon at the VNTR loci OtSL1 and Ssa1 for two stocks (Robertson Creek (RC) adults and Nicola River (NR) parr)

\begin{tabular}{lclcc}
\hline Locus & Stock & \multicolumn{1}{c}{ Phenotype } & $\begin{array}{c}\text { Heterozygosity } \\
(\%)\end{array}$ & $\begin{array}{c}\text { Sample } \\
\text { size }\end{array}$ \\
\hline OtSL1 & \multirow{2}{*}{ RC } & Mature (jacks) & 85.1 & 74 \\
& & Immature(females) & 87.2 & 94 \\
& NR & Precocious parr & 57.6 & 45 \\
& & Immature parr & 73.2 & 56 \\
Ssa1 & \multirow{2}{*}{ RC } & Mature (jacks) & 79.1 & 67 \\
& \multirow{2}{*}{ NR } & Immature(females) & 90.3 & 72 \\
& & Precocious parr & 93.1 & 43 \\
& & Immature parr & 92.9 & 56 \\
\hline
\end{tabular}

that two single locus VNTR DNA probes were sensitive enough to identify consistent differences between phenotypes in random-mated populations. These results support the assumption of a genetic component in the application of ESS theory to jacking in coho salmon (Gross, 1985).

There were no significant differences between the allele frequency distributions of the precocious and immature NR parr at the OtSL1 and Ssa1 loci. There is evidence for family or stock effects on this trait in other chinook salmon populations (Bernier et al., 1993; Taylor, 1989), however it is possible that there is no genetic component to the incidence of precocious parr in the NR stock. One limitation of our analyses was that nonsignificant results are particularly ambiguous due to the highly conservative nature of the analysis: First, as a nonparametric analysis, the log-linear model is inherently conservative (Sokal \& Rohlf, 1981) and, second, the use of relatively wide bin widths for the allele binning probably suppresses some allelic variation (i.e. true allele differences are binned together).

Low levels of allelic variation in the NR parental generation at the OtSL1 and Ssa1 loci would greatly reduce the probability of observing allele distribution differences in the offspring. Inspection of the allele frequency histograms of the NR parr (Fig. 3) provides evidence that the parents of the sampled NR parr were, in fact, fairly related. The NR parr had considerably fewer alleles than the RC adult chinook salmon at the OtSL1 locus (see Fig. 2), and furthermore, the NR parr had one or two extremely common alleles at both the OtSLl and Ssa1 loci. It is difficult to determine whether an increased sample size would have yielded significant results for the NR fish. However, since only 101 NR parr were analysed (vs. $168 \mathrm{RC}$ salmon), and the NR population was derived from three times the number of pair matings as the RC stock ( 45 vs. 15 ), the $\mathrm{NR}$ analysis was inherently less sensitive than the RC analysis. Nevertheless, our results do indicate that the NR chinook salmon population at the Spius Creek hatchery is probably not a good candidate for an extensive breeding experiment designed to test for the heritability of precocious maturation.

The mean heterozygosity at the OtSL1 and Ssa1 loci were comparable to other single locus VNTR DNA probes (Henke et al., 1991; Jeffreys et al., 1991). There were no differences between the maturing and randomly selected immature fish in heterozygosity for either stock or locus examined. Since the analysis of the allele frequency distribution showed a difference between the jacks and the females in the RC stock at both loci, whereas no differences in heterozygosity were found, changes in allele distribution are evidently more sensitive indicators of genetic subsets within a population.

Two points of caution concerning our analyses should be noted. First, our analyses were based on two anonymous loci, thus heterozygosity estimates based on these two loci do not reflect the whole genome. Further, the two loci have not been mapped or checked extensively for linkage with phenotypes. Nevertheless, since both OtSL1 and Ssa1 are VNTR DNA-associated probes, they probably behave similarly to VNTR loci in humans, and hybridize with noncoding or 'neutral' areas of the genome (Castelli et al., 1990), and they can thus be used as unbiased measures of kinship or relatedness.

The analysis of the allele frequency distributions of phenotypes of interest (in this case, precocious sexual maturation in the male chinook salmon) in randommated populations has a number of important potential applications. Allele frequency distributions could be used to screen wild populations for family effects on traits of interest prior to the implementation of intensive breeding programmes. In theory, any measurable phenotypic trait could be used, however quantitative 
traits would have to be divided into distinct groups (e.g. 'large', 'medium', and 'small' for size differences). There are many species that cannot easily be reared in captivity, although for some it may still be simpler to design and implement a traditional breeding programme.

This study examined family effects on a specific trait within two random-mated populations using DNAbased technology. This type of analysis in groups of plants and animals should prove to be a valuable approach for studying natural populations, especially those that cannot be selectively bred or easily reared in captivity.

\section{Acknowledgments}

We would like to thank Dr P. Bentzen (University of Washington, Seattle, WA.) for kindly providing the Ssa1 SLP probe. Drs T. A. Mousseau, T. J. Hilbish and C. Walters provided helpful advice and comments. $M$. Englesjord, N. Bernier, J. Smit, V. A. Heath, M. Wiggins, T. Yesaki, and N. Johnson provided valuable help in the laboratory and field. Funding for this project was provided by a Department of Fisheries and Oceans, Canada operating grant to R.H.D.; operating grants from Natural Science and Engineering Research Council, Canada and the Canadian Bacterial Diseases Network to G.K.I.; and by Yellow Island Aquaculture Ltd. Personal funding for D.D.H. was provided by the Science Council of British Columbia.

\section{References}

AMOS, B., BARRETT, J. AND DOVER, G. A. 1991. Breeding behaviour of pilot whales revealed by DNA fingerprinting. Heredity, 67, 49-55.

BALAZS, 1., NEUWEILER, J., GUNN, P., KIDD, J., KIDD, K. K., KUHL, J. AND MINGJUN, L. 1992. Human population genetic studies using hypervariable loci. I. Analysis of Assamese, Australian, Cambodian, Caucasian, Chinese and Melanesian populations. Genetics, 131, 191-198.

BENTZEN, P. A. AND WRiGHT, J. M. 1993. Nucleotide sequence and evolutionary conservation of a minisatellite variable number tandem repeat cloned from Atlantic salmon, Salmo salar. Genome, 36, 271-277.

BENTZEN, P., HARRIS, A. AND WRIGHT, J. M. 1991. Cloning of hypervariable minisatellite and simple sequence microsatellite repeats for DNA fingerprinting of important aquacultural species of salmonids and tilapia. In: Burke, T., Dolf, G., Jeffreys, A. J. and Wolff, R. (eds) DNA Fingerprinting: Approaches and Applications, pp. 243-262. Birkhäuser Verlag, Basel.

BERNIER, N. J., HEATH, D. D., RANDALL, D. J. AND IWAMA, G. K. 1993. Repeat sexual maturation of precocious male chinook salmon (Oncorhynchus tshawytscha) transferred to sea water. Can.J. Zool., 71, 683-688.
BOHLiN, T., DELLEFors, C. AND FAREMO, U. 1986. Early sexual maturation of male sea trout and salmon - an evolutionary model and some practical implications. Rep. Inst. Freshw. Res. Drottningholm, 63, 17-25.

BURKE, T., HANOTTE, O., BRUFORD, M. W. AND CAIRNS, E. 1991. Multilocus and single locus minisatellite analysis in population biological studies. In: Burke, T, Dolf, G., Jeffreys, A. J. and Wolff, R. (eds) DNA Fingerprinting: Approaches and Applications, pp. 154-168. Birkhäuser Verlag, Basel.

CASTELLI, M., PHILIPPART, J., VASSART, G. AND GEORGES, M. 1990. DNA fingerprinting in fish: a new generation of genetic markers. Am. Fish. Soc. Symposium, 7, 514-520.

DEVLIN, R. H., McNEIL, B. K., GROVES, D. D. AND DONALDSON, E. M. 1991. Isolation of a Y-chromosomal DNA probe capable of determining genetic sex in chinook salmon (Oncorhynchus tshawytscha). Can. J. Fish. Aquat. Sci., 48, 1606-1612.

FEINBERG, A. P. AND Vogelstein, B. 1984. Addendum. Analyt. Biochem., 137, 266-267.

FIENBERG, S. E. 1970. The analysis of multidimensional contingency tables. Ecology, 51, 419-433.

GILBERT, D. A., LEHMAN, N., O'BRIEN, S. J. AND WAYNE, R. K. 1990. Genetic fingerprinting reflects population differentiation in the California Channel Island fox. Nature, 344, 764-767.

GROSS, M. R. 1985. Disruptive selection for alternative life histories in salmon. Nature, 313, 47-48.

HANOTTE, O., BURKE, T., ARMOUR, J. A. L. AND JEFFREYS, A. J. 1991. Cloning, characterization and evolution of Indian peafowl, Pavo christatus, minisatellite loci. In: Burke, T., Dolf, G., Jeffreys, A. J. and Wolff, R. (eds) DNA Fingerprinting: Approaches and Applications, pp. 193-216. Birkhäuser Verlag, Basel.

HEALEY, M. C. 1991. Life history of chinook salmon (Oncorhynchus tshawytscha). In: Groot, C. and Margolis, L. (eds) Pacific Salmon Life Histories, pp. 311-394. UBC Press, Vancouver.

HEATH, D. D., HEATH, J. W. AND IWAMA, G. K. 1991. Maturation in chinook salmon, Oncorhynchus tshawytscha (Walbaum): early identification based on the development of a bimodal weight-frequency distribution. J. Fish Biol., 39, 565-575.

HEATH, D. D., IWAMA, G. K. AND DEVLIN, R. H. 1993a. PCR primed with VNTR core sequences yields species specific patterns and hypervariable probes. Nucl. Acids Res., 21, 5782-5785.

HEATH, D. D., BERNIER, N. J., HEATH, J. W. AND IWAMA, G. K. 1993 b. Genetic, environmental, and interaction effects on growth and stress response of chinook salmon (Oncorhynchus tshawytscha) fry. Can. J. Fish. Aquat. Sci., 50, 435-442.

HEATH, D. D., DEVLIN, R. H., HEATH, J. W. AND IWAMA, G. K. 1994. Genetic, environmental, and interaction effects on the incidence of jacking in chinook salmon (Oncorhynchus tshawytscha). Heredity, 72, 146-154.

HENKE, L., CLEEF, S., ZAKRZEWSKA, M. AND henKe, J. 1991. Population genetic data determined for five different single locus minisatellite probes, In: Burke, T., Dolf, G., Jeffreys, A. J. and Wolff, R. (eds) DNA Fingerprinting: Approaches and Applications, pp. 144-153. Birkhäuser Verlag, Basel. 
JARMAN, A. P. AND WELLS, R. A. 1989. Hypervariable minisatellites: recombinators or innocent bystanders? Trends Genet., 5, 367-371.

JEFFREYS, A. J., MACLEOD, A., TAMAKI, K., NEIL, D. L. AND MONCKTON, D. G. 1991. Minisatellite repeat coding as a digital approach to DNA typing. Nature, 354, 204-209.

KEMPENAERS, B., VERHEYEN G. R., VAN DEN BROECK, M., BURKE, T., VAN BROECKHOVEN, C. AND DHONDT, A. A. 1992. Extra-pair paternity results from female preference for high-quality males in the blue tit. Nature, 357, 494-496.

LEONARDSSON, K. AND LUNDBERG, P. 1986. The choice of reproductive tactics as a mixed evolutionary stable strategy: the case of male Atlantic salmon (Salmo salar L.). Rep. Inst. Freshw. Res., Drottningholm, 63, 69-76.

LYNCH, M. 1991. Analysis of population genetic structure by DNA fingerprinting. In: Burke, T., Dolf, G., Jeffreys, A. J. and Wolff, R. (eds) DNA Fingerprinting: Approaches and Applications, pp. 113-126. Birkhäuser Verlag, Basel.

PASCALI, v. L., dALOJA, E., DOBOSZ, M AND PESCARMONA, M. 1991. Estimating allele frequencies of hypervariable DNA systems. Forensic Sci. Int., 51, 273-280.

ROBERTSON, O. H. 1957. Survival of precociously mature king salmon male parr (Oncorhynchus tshawytscha juv.) after spawning. Calif. Fish Game, 43, 119-130.

RogSTAD, S., WOLFF, K. AND SCHAAL, B. A. 1991. Geographical variation in Asimina triloba Dunal (Annonaceae) revealed by the M13 'DNA fingerprinting' probe. Am. J. Bot., 78, $1391-1396$.

SAMBROOK, J., FRITSCH, E. F. AND MANIATIS, T. 1989. Molecular Cloning: A Laboratory Manual, 2nd edn. Cold Spring Harbor Laboratory Press, Cold Spring Harbor.

SCHAFFER, W. M. AND ELSON, P. F. 1975. The adaptive significance of variations in life history among local populations of Atlantic salmon in North America. Ecology, 56, 577-590.

SOKAL, R. R. AND ROHLF, F. J. 1981. Biometry, 2nd edn. W.H. Freeman \& Co., San Francisco.

STEPHAN, W. AND CHO, S. 1994. Possible role of natural selection in the formation of tandem-repetitive non-coding DNA. Genetics, 136, 333-341.

TAGgART, J. B. AND FERGUSON, A. 1990. Hypervariable minisatellite DNA single locus probes for the Atlantic salmon, Salmo salar L. J. Fish Biol., 37, 991-993.

TAYLOR, E. B. 1989. Precocial male maturation in laboratoryreared populations of chinook salmon, Oncorhynchus tshawytscha. Can. J. Zool., 67, 1665-1669.

TRIGGS, S. J., WILLIAMS, M. J., MARSHALL, S. J. AND CHAMBERS, G. K. 1992. Genetic structure of blue duck (Hymenolaimus malacorhunchos) populations revealed by DNA fingerprinting. Auk, 109, 80-89.

TYNAN, K. M., PARSLOW, M. I. AND HOAR, D. I. 1991. Genetic stability of the D1Z2 region: implications for DNA genotyping and paternity testing. Genome, 34, 733-738.

WESTNEAT, D. F., NOON, W. A., REEVE, H. K. AND AQUADRO, C. F. 1988. Improved hybridization conditions for DNA 'fingerprints' probed with M13. Nucl. Acids Res., 16, 4161.

WIRGIN, 1. 1., GRUNWALD, C. AND GARTE, S. J. 1991. Use of DNA fingerprinting in the identification and management of a striped bass population in the southeastern United States. Trans. Am. Fish. Soc., 120, 273-282.

WOLFF, R., NAKAMURA, Y., ODELBERG, S., SHIANG, R. AND WHITE, R. 1991. Generation of variability at VNTR loci in human DNA. In: Burke, T., Dolf, G., Jeffreys, A. J. and Wolff, R. (eds) DNA Fingerprinting: Approaches and Applications, pp. 20-38. Birkhäuser Verlag, Basel. 